Vol 4 No 1 Januari 2021

\title{
PENELITIAN
}

\section{Prevalensi Pengguna Jaminan Kesehatan Nasional Pada Pasien Diabetes Mellitus Tipe 2 Di RSU Muhammadiyah Sumatera Utara Tahun 2017}

\author{
Muhammad Azhari Rangkuti ${ }^{1}$, Ilham Hariaji ${ }^{2}$ \\ ${ }^{1}$ Fakultas Kedokteran Universitas Muhammadiyah Sumatera Utara \\ Email: azharirangkuti27@gmail.com
}

\begin{abstract}
Abstrak : Latar Belakang: Berdasarkan Undang-Undang Dasar Negara Republik Indonesia pasal $28 \mathrm{H}$ ayat 1 dan 34, dikeluarkanlah kebijakan Jaminan Kesehatan Nasional yang diselenggarakan oleh Badan Penyelenggara Jaminan Sosial (National Health Care Organization). Kebijakan tersebut mendapat respon positif dari masyarakat. Pada tahun 2017, Indonesia menduduki peringkat ke-2 populasi diabetes melitus tipe2.Penelitian ini bertujuan untuk mengetahui proporsi pengguna Jaminan Kesehatan Nasional pada Diabetes Mellitus tipe2. Metode :Penelitian deskriptif menggunakan metode Cross Sectional. Sampel dalam penelitian ini adalah rekam medis di RSUD Muhammadiyah Sumatera Utara tahun 2017 sebanyak 77 sampel. Hasil: Dari penelitian terhadap 585 sampel didapatkan 77 sampel yang memenuhi kriteria penelitian. Pengguna Jaminan Kesehatan Nasional menurut kelompok jenis kelamin terbanyak adalah perempuan / perempuan: 53 orang $(68,83 \%)$ dan paling sedikit adalah laki-laki / laki-laki: 25 orang $(31,17 \%)$. Pengguna Jaminan Kesehatan Nasional menurut kelompok umur terbanyak adalah kelompok umur terakhir (56-65 tahun): 29 orang (37,66\%), dan paling sedikit adalah remaja terakhir (17-25 tahun): 1 orang $(1,30 \%)$. Kesimpulan: Berdasarkan hasil penelitian, pengguna Jaminan Kesehatan Nasional untuk penderita diabetes melitus tipe 2 didominasi oleh perempuan dan usia tua (56-65 tahun).

Kata kunci: diabetes melitus tipe 2, jaminan kesehatan nasional, umur, jenis kelamin
\end{abstract}

\section{Prevalence Of National Health Assurance Users In Type 2 Diabetes Mellitus Patients At North Sumatera North Muhammadiyah Hospital, 2017}

\begin{abstract}
Background: Based on the constitution of the republic of indonesia chapter $28 H$ verse 1 and 34, issued a policy of National Health Insurance which organized by Badan Penyelenggara Jaminan Sosial (National Health Care Organization). The policy is gained positive response from the public.. In 2017, Indonesian was in the 2 nd rank of diabetes mellitus type 2 population. The research aimed to know proportion of National Health Assurance users on Diabetes Mellitus type 2. Method: The descriptive research uses Cross Sectional method. The sample got in the research are medical record in Muhammadiyah General Hospital North Sumatera in 2017, 77 samples.Result: From the research on 585 samples, there are on 77 samples which match the research standard/criteria. The most user of National Health Insurance based on gender group are females/women : 53 persons (68,83\%), and the least user are males/men : 25 persons $(31,17 \%)$. The most user of National Health Insurance based on age group are the last old aged (56-65 yerars old) : 29 persons $(37,66 \%)$, and the last users are the last teenagers $(17-25$ years old) : 1 person $(1,30 \%)$ Conclution: Based on the research, the National Health Insurance users for type 2 diabetes mellitus patients dominated by women and last sennior citizen (56-65 years old).
\end{abstract}

Keywords: diabetes mellitus type 2, national health insurance, age, gender 


\section{PENDAHULUAN}

Pada dasarnya setiap manusia memiliki hak untuk mendapatkan penjaminan dalam bidang kesehatan. Di Indonesia, hal tersebut diatur dalam UUD tahun 1945 pasal $28 \mathrm{H}$ ayat 1 dan pasal 34 , yang menerangkan bahwasannya setiap rakyat dijamin kesehatannya oleh Negara tanpa adanya pengecualian. Dengan adanya aturan dasar tersebut, Indonesia mengeluarkan kebijakan berupa Jaminan Kesehatan Nasional (JKN) pada tanggal 1 Januari 2014 yang dikelola oleh Badan Penyelenggara Jaminan Sosial. Harapan pemerintah dengan adanya kebijakan ini, pada tahun 2019 seluruh rakyat Indonesia telah terdaftar dan menjadi peserta JKN. ${ }^{1}$

Dalam pelaksanaan program JKN, pemerintah menerapkan aturan perujukan bertahap yang dimulai dari fasilitas pelayanan kesehatan primer (Fasyankes Primer) sampai ke fasilitas pelayanan kesehatan tingkat lanjutan yaitu rumah sakit. Tindakan yang dilakukan pihak Fasyankes Primer hanya bersifat upaya peningkatan kesehatan serta pencegahan penyakit, sedangkan tindakan yang ada di rumah sakit mengarah kepada upaya pengobatan dan pemulihan penyakit. ${ }^{2}$

Program ini awalnya mendapat respon positif dari berbagai kalangan masyarakat terutama bagi masyarakat yang mengalami penyakit Diabetes Mellitus tipe 2. Perlu untuk diketahui bahwasannya Diabetes Mellitus tipe 2 (DM tipe 2) ini merupakan suatu gangguan metabolisme yang ditandai dengan adanya kenaikan kadar gula darah akibat penurunan sekresi insuin oleh sel beta pankreas atau karena adanya gangguan fungsi insulin (resistensi insulin). ${ }^{3,4}$

Dalam undang-undang nomor 40 tahun 2004 tentang Sistem Jaminan Sosial Nasional (SJSN) pada pasal 22 ayat 1 dijelaskan bahwa manfaat dari program JKN mencakup pelayanan kesehatan yang bersifat promotif dan preventif. Bagi masyarakat yang mederita penyakit DM tipe 2, melalui JKN ini pemerintah memberikan pelayanan berupa skrining kesehatan untuk mendeteksi faktor risiko dan mencegah terjadinya komplikasi. ${ }^{5,6}$

Berdasarkan data International Diabetes Federation (IDF) untuk regio pasifik barat pada tahun 2017, Indonesia menempati urutan ke-2 dengan jumlah 10.578.401 penderita di rentang usia 18 99 tahun. Negara yang menempati urutan pertama adalah Cina dengan jumlah 120.907.995 penderita dan di urutan ke-3 
adalah Jepang dengan jumlah 8.343.288 penderita. ${ }^{7}$

Pada data Riset Kesehatan Dasar tahun 2013. Kejadian DM tipe 2 yang terdiagnosis umumnya sering terjadi di usia 55-64 tahun yang jumlahnya adalah $4,8 \%$ dari total seluruh jumlah penduduk Indonesia. Angka kejadian yang paling sedikit tempati oleh penduduk berusia 1524 tahun dengan jumlah $0,1 \%$ total penduduk Indonesia. ${ }^{8}$

Dari data itu juga dapat diperoleh jumlah kejadian DM tipe 2 berdasarkan jenis kelamin dan juga status pekerjaan. Untuk jenis kelamin sendiri perbandingan antara laki - laki dan perempuan, didapatkan hasil bahwasannya perempuan lebih banyak menderita DM tipe 2. Pada kategori status pekerjaan, penduduk yang bekerja sebagai wiraswasta lebih umum menderita DM tipe 2 dibandingkan penduduk yang bekerja lain, seperti: pegawai, petani, nelayan, buruh, ataupun yang sama sekali tidak bekerja. ${ }^{8}$

Berdasarkan penelitian sebelumnya yang dilakukan di Kota Manado. Menunjukkan bahwasannya masyarakat berjenis kelamin perempuan tidak memanfaatkan adanya BPJS. Untuk kategori usia dengan mengambil median usia 42 tahun, didapati usia $\leq 42$ tahun tidak memanfaatkan BPJS. ${ }^{9}$

Dari penelitian tersebut juga ditemukan jumlah masyarakat yang memanfaatkan BPJS ditinjau dari pekerjaanya. Status pekerjaan dibagi menjadi 2 yaitu bekerja dan tidak bekerja, dimana masyarakat yang bekerjalah yang tidak memanfaatkan BPJS. ${ }^{9}$

Atas dasar inilah peneliti ingin meneliti jumlah pengguna JKN berdasarkan usia dan jenis kelamin pada pasien DM tipe 2 di RSU Muhammadiyah Sumatera Utara tahun 2017.

\section{METODE}

Penelitian ini merupakan penelitian deskriptif dengan menggunakan metode Cross Sectional yang variabelnya terdiri dari: Pasien DM tipe 2, Pengguna JKN, Jenis kelamin dan Usia.

RSU Muhammadiyah Sumatera Utara menjadi pilihan tempat dilakukannya penelitian ini dan berlangsung mulai bulan Oktober 2018 sampai dengan bulan Desember 2018.

Sampel yang digunakan dalam penelitian ini berupa rekam medis pasien DM tipe 2 tahun 2017 di Poli Penyakit Dalam RSU Muhammadiyah Sumatera Utara yang sesuai dengan kriteria inklusi 
dan tidak merupakan bagian dari kriteria eksklusi. Kriteria inklusi dalam pelenitian ini adalah Rekam medis pasien DM tipe 2 yang memuat variabel yang akan diteliti dengan lengkap, sedangkan kriteria eksklusinya adalah Pasien DM tipe 2 yang berobat secara mandiri atau menggunakan jasa asuransi kesehatan selain BPJS Kesehatan.

Besaran sampel yang diperlukan selama dilakukannya penelitian ini adalah 71 data sekunder dari Poli Penyakit Dalam RSU Muhammadiyah Sumatera Utara Tahun 2017.

\section{HASIL}

Data yang diambil berupa rekam medis pasien Diabetes Mellitus tipe 2 yang dalam upaya pembiayaan biaya pengobatannya menggunakan jasa BPJS Kesehatan yang merupakan JKN di RSU Muhammadiyah Sumatera Utara. Rekam medis yang digunakan sebagai data sekunder penelitian ini diambil dari bulan Januari tahun 2017 sampai dengan bulan Desember tahun 2017.

Diperoleh sebanyak 585 data rekam medis dari Poli Penyakit Dalam RSU Muhammadiyah Sumatera Utara, namun yang sesuai dengan kriteria inklusi hanya 77 data.
Tabel 1 Distribusi pengguna JKN pada pasien DM tipe 2 berdasarkan jenis kelamin

\begin{tabular}{lll}
\hline $\begin{array}{l}\text { Jenis } \\
\text { Kelamin }\end{array}$ & Frekuensi & Persentase \\
\hline Laki-laki & 24 & 31,17 \\
Perempuan & 53 & 68,83 \\
\hline Total & 77 & 100 \\
\hline
\end{tabular}

Berdasarkan Tabel 1 dapat diketahui bahwasannya frekuensi tertinggi pengguna JKN pada pasien Diabetes Mellitus tipe 2 di RSU Muhammadiyah Sumatera Utara tahun 2017 adalah pasien berjenis kelamin perempuan yaitu sebesar 53 orang $(68,83 \%)$, sedangkan pasien dengan jenis kelamin laki-laki menjadi frekuensi yang terendah yaitu sebesar 24 orang $(31,17 \%)$.

Tabel 2 Distribusi pengguna JKN pada pasien DM tipe 2 berdasarkan usia

\begin{tabular}{lll}
\hline Usia (tahun) & Frekuensi & Persentase \\
\hline $\begin{array}{l}\text { Remaja(17- } \\
\text { 25 ) }\end{array}$ & 1 & 1,30 \\
$\begin{array}{l}\text { Dewasa } \\
\text { awal (26-35 }\end{array}$ & 5 & 6,49 \\
$\begin{array}{l}\text { Dewasa } \\
\text { Dahir (36- }\end{array}$ & 4 & 5,20 \\
$\begin{array}{l}\text { 45) } \\
\text { Lansia awal }\end{array}$ & 23 & 29,87 \\
$\begin{array}{l}\text { (46-55) } \\
\text { Lansia } \\
\text { akhir (56-65 }\end{array}$ & 29 & 37,66 \\
) & & \\
$\begin{array}{l}\text { Manula(>65 } \\
\text { ) }\end{array}$ & 15 & 19,48 \\
\hline Total & 77 & 100 \\
\hline
\end{tabular}


Pada Tabel 4.2 menunjukkan bahwa kelompok usia yang paling banyak pengguna JKN pada pasien diabetes mellitus tipe 2 adalah lansia akhir dengan rentang usia 56-65 tahun yang berjumlah 29 orang $(37,66 \%)$, dan kelompok usia yang paling sedikit adalah remaja akhir dengan rentang usia 17-25 tahun yang jumlahnya 1 orang $(1,30 \%)$.

\section{DISKUSI}

Berdasarkan rekam medis pasien di RSU Muhammadiyah Sumatera Utara tahun 2017 diperoleh jumlah pasien Diabetes Mellitus tipe 2 yang menggunakan Jaminan Kesehatan Nasional sebanyak 77 orang.

Hasil penelitian yang ada pada tabel 4.1 yaitu distribusi pengguna JKN pada pasien Diabetes Mellitus tipe 2 berdasarkan jenis kelamin yang tercatat di rekam medis RSU Muhammadiyah Sumatera Utara tahun 2017 didapati distribusi perempuan sebanyak 53 orang $(68,83 \%)$ dan laki-laki sebanyak 24 orang $(31,17 \%)$. Data ini menunjukkan bahwa umumnya pengguna JKN pada pasien DM tipe 2 berjenis kelamin perempuan.

Berdasarkan penelitian yang dilakukan Deny Kurniawan di Puskesmas Tamalanrea Jaya tahun 2016, menjadi bukti bahwa banyaknya pengguna JKN di dominasi oleh masyarakat yang berjenis kelamin perempuan dimana jumlahnya sendiri ada 60 dari 100 responden. ${ }^{10}$

Pada penelitian yang dilakukan oleh Fitsum Girma dkk di South West Ethiopia, dapat disimpulkan bahwa masyarakat yang berjenis kelamin laki-laki hampir 0,23 kali lebih sedikit dibandingkan masyarakat berjenis kelamin perempuan dalam hal pemanfaatan pelayanan kesehatan. Dikatakan demikian karena pada umumnya masyarakat yang berjenis kelamin perempuan lebih rentan untuk terserang berbagai penyakit terutama penyakit yang berhubungan dengan reproduksi. Hal lain yang berkaitan dengan banyaknya pemanfaatan pelayanan kesehatan dikalangan perempuan karena perempuan atau lebih tepatnya disebut kaum ibu lebih sering membawa anaknya untuk berobat. ${ }^{11}$

Menurut penelitian Fera F. Liuw di Kelurahan Kolongan Kecamatan Tomohon Tengah Kota Tomohon, mendukung hasil penelitian ini dimana banyaknya penderita DM tipe 2 yang berjenis kelamin perempuan. Penelitian tersebut memperoleh 66 responden perempuan dari total 96 responden. ${ }^{12}$ 
Hasil penelitian Fera F. Liuw tersebut sejalan dengan penelitian yang dilakukan oleh Desy L. Allorerung di Puskesmas Ranotana Weru Kota Manado tahun 2016 yang mengatakan bahwa perempuan memilki risiko terkena DM tipe 2 sebesar 2,777 kali dibanding laki-laki. Hal yang menyebabkan wanita lebih cendrung terkena DM tipe 2 berhubungan dengan kehamilan dimana kehamilan merupakan faktor risiko terjadinya Diabetes Mellitus. ${ }^{12,13}$

Dari penelitian yang dilakukan oleh Fahrudi tahun 2013, jenis kelamin mempengaruhi kadar glukosa darah karena perubahan persentase komposisi lemak tubuh pada perempuan tepatnya disaat usia lansia dimana dapat menurunkan sensitifitas insulin. Perubahan komposisi lemak pada perempuan yang telah mengalami menopause terjadi karena kadar hormon estrogen dan progesteron yang menurun. ${ }^{14}$ Hasil penelitian yang ada pada tabel 4.2 yaitu distribusi pengguna JKN pada pasien Diabetes Mellitus tipe 2 berdasarkan usia yang tercatat di rekam medis RSU Muhammadiyah Sumatera Utara tahun 2017 didapati distribusi kelompok usia lansia akhir (56-65 tahun) adalah kelompok usia terbanyak menderita DM tipe 2 dengan jumlah 29 orang (37,66\%) kemudian diikuti kelompok usia Lansia Awal (46-55 tahun) yang jumlahnya 23 orang $(29,87 \%)$ dan terbanyak terakhir ada pada kelompok usia Manula ( $>65$ tahun) yang jumlahnya 15 orang $(19,48 \%)$. Pada kelompok usia yang paling sedikit menderita DM tipe 2 adalah Remaja Akhir (17-25 tahun) yaitu berjumlah 1 orang $(1,30 \%)$.

Ditinjau dari penelitian sebelumnya yang dilakukan di Puskesmas Tahuna Barat, menyatakan bahwa terdapat hubungan antara pengguna JKN dengan usia masyarakat. Pada penelitian tersebut didapatkan kelompok tertinggi yang menggunakan JKN adalah kelompok usia 38-57 tahun yang jumlahnya 47 responden $(47,0 \%)$ dan yang terendah ada pada kelompok usia 78-97 tahun yang berjumlah 6 responden $(6,0 \%){ }^{15}$

Berdasarkan pada penelitian Atika Dalili Akhmad yang menyebutkan bahwa usia produktif dan usia lanjut akan lebih banyak menggunakan fasilitas kesehatan. ${ }^{16}$

Ditinjau dari usia yang umumnya menderita panyakit DM tipe 2 pada penelitian yang dilakukan oleh Evi Kurniawaty menyebutkan bahwa usia 50 $\geq$ dapat meningkatkan kejadian DM tipe 2 
karena penuaan menyebabkan menurunnya sensitivitas insulin dan menurunnya fungsi tubuh untuk metabolisme glukosa. Hasil penelitian tersebut sejalan dengan hasil penelitian yang dilaksanakan John S. Kekenusa yang menunjukkan bahwa umur yang berhubungan dengan kejadian penyakit DM tipe 2 adalah umur $\geq 45$ tahun yang respondennya berjumlah 135 orang $(56,2 \%){ }^{17}$

Menurut Prof. Reaven dan deFronzo ternyata memang ada resistensi insulin perifer yang menandai $\mathrm{DM}$ tipe 2 pada kelompok usia lanjut. Menurutnya toleransi glukosa pada usia lanjut ini berhubungan dengan berkurangnya senstivitas sel perifer terhadap insulin (resistensi insulin). Ada juga faktor sekunder yaitu: perubahan pola hidup dan timbulnya penyakit lain. ${ }^{18}$

Dalam KONSENSUS PERKENI menyebutkan bahwa usia $>45$ tahun merupakan kelompok yang berisiko tinggi untuk menderita DM tipe $2 .{ }^{19}$

\section{KESIMPULAN}

Berdasarkan hasil penelitian tentang Prevalensi pengguna Jaminan Kesehatan Nasional pada pasien Diabetes Mellitus tipe 2 di RSU Muhammadiyah Sumatera
Utara tahun 2017, dapat diambil kesimpulan bahwa:

1. Berdasarkan jenis kelamin pengguna JKN yang menderita DM tipe 2, distribusi tertinggi terdapat pada kelompok pasien yang berjenis kelamin perempuan dengan jumlah 53 orang $(68,83 \%)$ dan yang terendah adalah kelompok pasien yang berjenis kelamin laki-laki yang berjumlah 24 orang $(31,17 \%)$.

2. Pada peninjauan terhadap kelompok usia, pengguna JKN yang menderita penyakit DM tipe 2 tertinggi terdapat pada kelompok usia lansia akhir (56-65 tahun) sebanyak 29 orang $(37,66 \%)$, sedangkan kelompok usia terendah berada di kelompok usia remaja akhir (17-25 tahun) yang jumlahnya 1 orang $(1,30 \%)$.

\section{DAFTAR PUSTAKA}

1. Amira AY, Sudiro, Wigati PA. Evaluasi Pelaksanaan Sosialisasi Program Jaminan Kesehatan Nasional dari Aspek Struktur dan Interaksi Sosialisasi Pada Bulan Januari-Maret 2014 di Puskesmas Ngesrep Semarang. $J$ Kesehat 
Masy. 2015;3. http://ejournals1.undip.ac.id/index.php/jkm.

2. Presiden Republik Indonesia. Undang-Undang Nomor 24 Tahun 2011 Tentang Badan Penyelenggara Jaminan Sosial.; 2011. http:/bpjskesehatan.go.id/bpjs/dmdocuments /20e67493084e6d2e600888b1dd9f 94f4.pdf.

3. Fatimah RN. Diabetes Melitus tipe 2. $j$ Major. 2015;4:93-101. juke.kedokteran.unila.ac.id/index.p hp/majority/article/download/615/ 619.

4. Soewondo P. Harapan Baru Penyandang Diabetes Mellitus pada Era Jaminan Kesehatan Nasional 2014. eJKI. 2014;2. http://media.neliti.com/media/publ ication/59715-ID-harapan-barupenyandang-diabetes-melitus.pdf.

5. Presiden Republik Indonesia. Kumpulan Peraturan Jaminan Kesehatan.

www.depkes.go.id/resources/down load/jkn/himpunan-peraturanjaminan-kesehatan.pdf.

6. Idris F. Pengintegrasian Program Preventif Penyakit Diabetes Melitus Tipe 2 PT Askes (persero) ke Badan Penyelenggara Jaminan Sosial Kesehatan (BPJS Kesehatan). J Indon Med Assoc. $2014 ; 64$

eprints.unsri.ac.id/5313/1/Penginte grasian_Program_Preventif.pdf.

7. International Diabetes Federation. IDF Diabetes Atlas - Western Pasific.; 2017. diabetesatlas.org/component/attach ment/?task=download\&id=268.

8. Kementerian Kesehatan Republik Indonesia. Riset Kesehatan Dasar.; 2013.

www.depkes.go.id/resources/down load/general/Hasil Riskesdas 2013.pdf.

9. Rumengan DSS, Umboh JML, Kandou GD. Faktor-Faktor yang Berhubungan Dengan Pemanfaatan Pelayanan Kesehatan Pada Peserta BPJS Kesehatan di Puskesmas Paniki Bawah Kecamatan Mapanget Kota Manado. JIKMU. $2015 ; 5$.

http://ejournal.unsrat.ac.id/index.p hp/jikmarticle/view/7180.

10. Kurniawan D, Abadi MY, Nurhayani. Faktor yang mempengaruhi masyarakat dalam pemanfaatan JKN di puskesmas 
Tamalanrea Jaya. 2016 . digilib.unhas.ac.id/uploaded_files/t emporary/DigitalCollection/ZGNh OGFiYjA5MTViN2U4YTRjNGF kMmFiY2ZiNDczMmViMTM3M TJIOA==.pdf.

11. Girma F, Jira C, Girma B. Health services utilization and associated factors in Jimma zone, South West Ethiopia. Ethiop $J$ Heal Sci. 2011;21:85-94.

https://www.ajol.info/index.php/ej hs/article/download/74273/64920.

12. Liuw FF, Kandou GD, Malonda NSH. Hubungan antara jenis kelamin dan diabetes mellitus tipe 2 dengan kualitas hidup pada penduduk di Kelurahan Kolongan Kecamatan Tomohon Tengah Kota Tomohon. 2017. ejournalhealth.com/index.php/med kes/article/download/323/315.

13. Allorerung DL, Sekeon sekplin AS, Joseph WBS. Hubungan antara umur, jenis kelamin dan tingkat pendidikan dengan kejadian diabetes melitus tipe 2 di puskesmas Ranotana Weru Kota Manado tahun 2016. 2016. medkesfkm.unsrat.ac.id/wpcontent/uploads/2016/11/JURNAL
-Desy-L.-Allorerung.pdf.

14. Reswan H, Alioes Y, Rita RS. Gambaran glukosa darah pada lansia di panti sosial tresna werdha sabai nan aluih sicincin. $J$ Kesehat Andalas. $2017 ; 6$. jurnal.fk.unand.ac.id/index.php/jka /article/download/756/612.

15. Londo JP, Tucunan AAT, Maramis FRR. Hubungan antara karakteristik peserta BPJS Kesehatan dengan pelayanan puskesmas di wilayah kerja puskesmas Tahuna Barat. 2017. ejournalhealth.com/index.php/kes mas/article/viewFile/403/396.

16. Akhmad AD, Satibi, Puspandari DA. Analisis persepsi dan faktor yang mempengaruhi persepsi terhadap penerapan sistem pembiayaan JKN pada fasilitas kesehatan penunjang di D. I. Yogyakarta. $J$ Manaj dan Pelayanan Farm. 2015;5:267-274. journal.ugm.ac.id/jmpf/article/vie w/29456/17600.

17. Kurniawaty E, Yanita B. Faktorfaktor yang berhubungan dengan kejadian diabetes melitus tipe II. Majority. 2016;5:27-31. juke.kedokteran.unila.ac.id/index.p 
hp/majority/article/download/1073

1912.

18. Djokomoeljanto R. Endokrinologi pada usia lanjut. In: Buku Ajar Budhi-Darmojo: Geriatri. 5th ed. Jakarta: Bpfkui; 2015:440-444.

19. PERKENI. Konsensus Pengolaan Dan Pencegahan Diabetes Melitus Tipe 2 Di Indonesia.; 2015. 